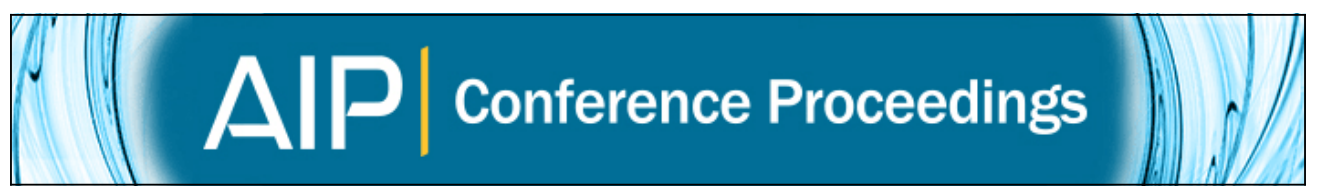

\title{
Keeping the History in Historical Seismology: The 1872 Owens Valley, California Earthquake
}

Susan E. Hough

Citation: AIP Conference Proceedings 1020, 293 (2008); doi: 10.1063/1.2963848

View online: http://dx.doi.org/10.1063/1.2963848

View Table of Contents:

http://scitation.aip.org/content/aip/proceeding/aipcp/1020?ver=pdfcov

Published by the AIP Publishing

\section{Articles you may be interested in}

Evaluation of Pseudo-Static Coefficients According to Performance-Based Criteria AIP Conf. Proc. 1020, 501 (2008); 10.1063/1.2963876

System Identification of Burbank Six-Story Building Using Earthquake Data AIP Conf. Proc. 1020, 1819 (2008); 10.1063/1.2963817

Use of shock block transmitters in the structural rehabilitation of historical buildings in Calabria and Sicily

AIP Conf. Proc. 1020, 1320 (2008); 10.1063/1.2963753

Three Dimensional Response Spectrum Soil Structure Modeling Versus Conceptual Understanding To Illustrate Seismic Response Of Structures

AIP Conf. Proc. 1020, 1143 (2008); 10.1063/1.2963734

The Challenge of Centennial Earthquakes to Improve Modern Earthquake Engineering AIP Conf. Proc. 1020, 1113 (2008); 10.1063/1.2963730 


\title{
Keeping the History in Historical Seismology: The 1872 Owens Valley, California Earthquake
}

\author{
Susan E. Hough \\ U.S. Geological Survey \\ 525 South Wilson Avenue \\ Pasadena, California 91106
}

\begin{abstract}
The importance of historical earthquakes is being increasingly recognized. Careful investigations of key pre-instrumental earthquakes can provide critical information and insights for not only seismic hazard assessment but also for earthquake science. In recent years, with the explosive growth in computational sophistication in Earth sciences, researchers have developed increasingly sophisticated methods to analyze macroseismic data quantitatively. These methodological developments can be extremely useful to exploit fully the temporally and spatially rich information source that seismic intensities often represent. For example, the exhaustive and painstaking investigations done by Ambraseys and his colleagues of early Himalayan earthquakes provides information that can be used to map out site response in the Ganges basin. In any investigation of macroseismic data, however, one must stay mindful that intensity values are not data but rather interpretations. The results of any subsequent analysis, regardless of the degree of sophistication of the methodology, will be only as reliable as the interpretations of available accounts - and only as complete as the research done to ferret out, and in many cases translate, these accounts. When intensities are assigned without an appreciation of historical setting and context, seemingly careful subsequent analysis can yield grossly inaccurate results. As a case study, I report here on the results of a recent investigation of the 1872 Owen's Valley, California earthquake. Careful consideration of macroseismic observations reveals that this event was probably larger than the great San Francisco earthquake of 1906, and possibly the largest historical earthquake in California. The results suggest that some large earthquakes in California will generate significantly larger ground motions than San Andreas fault events of comparable magnitude.
\end{abstract}

Keywords: Historical earthquakes, earthquake hazard

PACS: 91.30.Bi, 91.30.mv, 91.30.Px.

\section{INTRODUCTION}

Instrumental seismic data is non-existent for earthquakes prior to the late $19^{\text {th }}$ century, and strong motion data are sparse at best for earthquakes prior to the mid-20 $0^{\text {th }}$ century. Typically, especially in low-strain-rate areas, no instrumental data are available to investigate the largest historical earthquakes in a region. So-called macroseismic data have been shown to be of enormous value for determining source parameters as well as to investigate ground motions [e.g., 1, 2]. In recent years, sophisticated new methods have been developed to analyze intensity values quantitatively [e.g., 3, 4]. In these studies there is, or can be, a tendency to talk about

CP1020, 2008 Seismic Engineering Conference Commemorating the 1908 Messina and Reggio Calabria Earthquake, edited by A. Santini and N. Moraci

2008 American Institute of Physics 978-0-7354-0542-4/08/\$23.00 
"intensity data," a term that reflects a lack of appreciation for the nature of intensity values, and for key issues associated with their determination.

The interpretation of intensity values is moreover a critical step in its own right. Modern intensity scales take building vulnerability into account (see discussion in [2]), but values cannot be assigned without an appreciation of the historical context of each earthquake, including local building styles. Values also cannot be assigned without careful consideration of individual intensity indicators, some of which (for example, liquefaction and rockslides) have been recognized to be very poor indicators of overall shaking severity. Finally, any interpretation of macroseismic data must consider carefully the veracity and possible biases associated with archival sources, for example the fact that news accounts focus on dramatic rather than representative damage [e.g., 5].

Many early intensity assignments have been shown to be inappropriately high [e.g., $6]$ and to yield inflated estimates of magnitude. However, it is neither expected nor plausible that every historical earthquake is smaller than early studies suggest. I report here on a case in which careful reinterpretation reveals that the magnitude of an important earthquake, the Owen's Valley, California, earthquake of 26 March 1872, has generally been underestimated in earlier studies.

\section{THE OWENS VALLEY EARTHQUAKE}

The Owens Valley earthquake (hereinafter OV1872) occurred along the eastern flank of the Sierra Nevada range at approximately 2:30 in the morning, local time, on 26 March, 1872. By 1870 the population of the state of California had grown to over 560,000 , and a number of mining settlements, including Independence, Lone Pine, and Bishop Creek, had been established along Owens Valley (Figure 1a.) Population was sparse in the Owens Valley region at the time of the earthquake. For example, there were only about 500 voters (e.g., male citizens of any race, 21 years old and older) scattered between a half-dozen principle settlements [7].

The Owens Valley earthquake generated a dramatic surface rupture that was described crudely by Josiah Whitney $[8,9]$. Over a century later the surface rupture was mapped by Beanland and Clark [10] (hereinafter BC94), who identified a break $90-100 \mathrm{~km}$ in length, with an average right-lateral slip of $6 \mathrm{~m}$ and a total oblique slip of $6.1 \mathrm{~m}$. Later investigations [e.g., 11] conclude that the break extended approximately $17 \mathrm{~km}$ further south. Revisiting the contemporary account of Whitney [8], one finds that he describes "frequent cracks in the earth" as far south as Haiwee (Figure 1), and further notes as much as 4-5 ft of subsidence along the edge of Haiwee Meadows.

No surface break has been identified to the north of the northern terminus identified by BC94. However, early reports describe that the ground was pervasively cracked between Independence and Bishop Creek [12].

Instrumentally recorded background seismicity along the Owens Valley corridor reveals a striking gap that extends between Haiwee to the south and Bishop Creek to the north (Figure 1b). Thus both geological and seismological observations point to a significantly longer rupture than that mapped by BC94, 130 rather than $90-100 \mathrm{~km}$. A 
further note is that the rupture was clearly complex, with mapped breaks on multiple strands, and so the straight-line distance between the endpoints might underestimate the true length of the rupture.
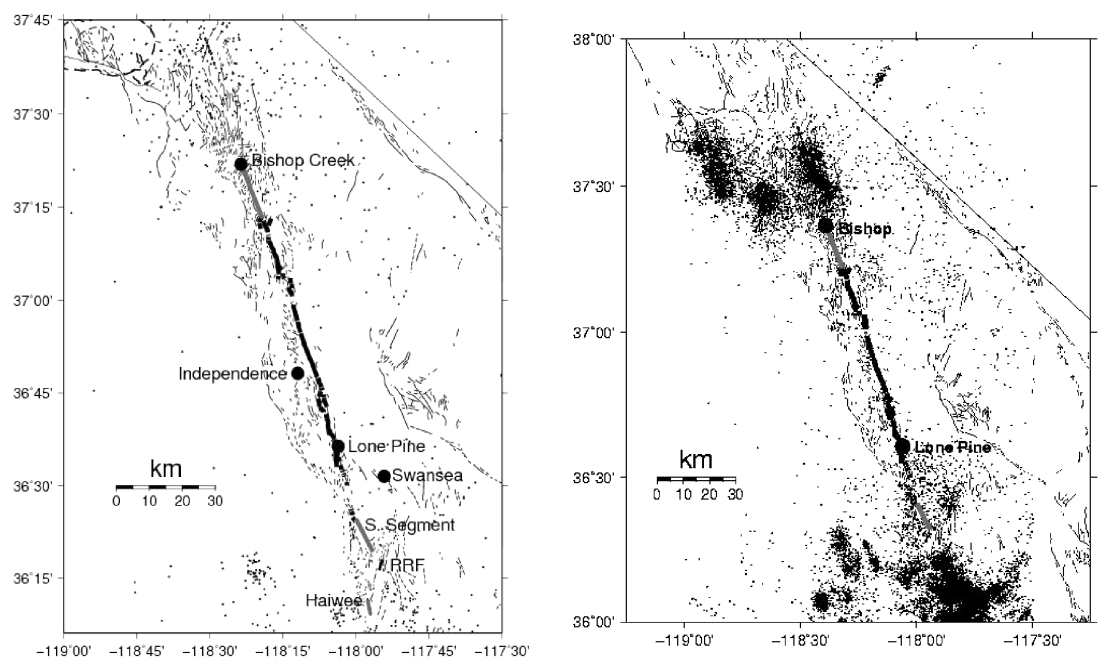

FIGURE 1. a) (left) The Owens Valley region and rupture of the 1872 earthquake, including break mapped by Beanland and Clark [10] (heavy black line) and possible extensions of the rupture (heavy grey lines.) b) (right) Instrumentally recorded earthquakes (small circles) between 1932 and 1990.

The depth extent of seismicity in the Owens Valley region is poorly constrained, with estimates ranging from 15 to $25 \mathrm{~km}$. Taking a rupture length of $130 \mathrm{~km}$, a depth of $20 \mathrm{~km}$, and the average slip reported by BC94, one infers $M_{w} 7.8$. Considering the uncertainties in rupture parameters, one estimates a range of $M_{w}$ 7.5-7.9.

\section{Macroseismic Observations}

As noted by authors in the early-to-mid $20^{\text {th }}$ century [e.g., 12], the Owens Valley earthquake "has generally been considered the largest known in the entire CaliforniaNevada region, thus placing it in magnitude above those of 1857 and 1906 on the San Andreas fault." Richter further noted that this assessment rests, "on the violence of effects over the large meizoseismal area, as well as perceptibility extending to great distances."

Archival accounts of OV1872 were compiled and interpreted in an earlier study [13]. Based on accounts that the earthquake stopped clocks and awakened many or most people throughout most of California, Toppozada et al. [13] assigns Modified Mercalli Intensity values of at least V throughout all but the northernmost $1 / 3$ of the state. It is now recognized, however, that the long-period waves from large regional earthquakes can stop pendulum clocks at intensities much lower than V [e.g., 14]. Further, data from the Community Internet Intensity Map website [15] reveal that 


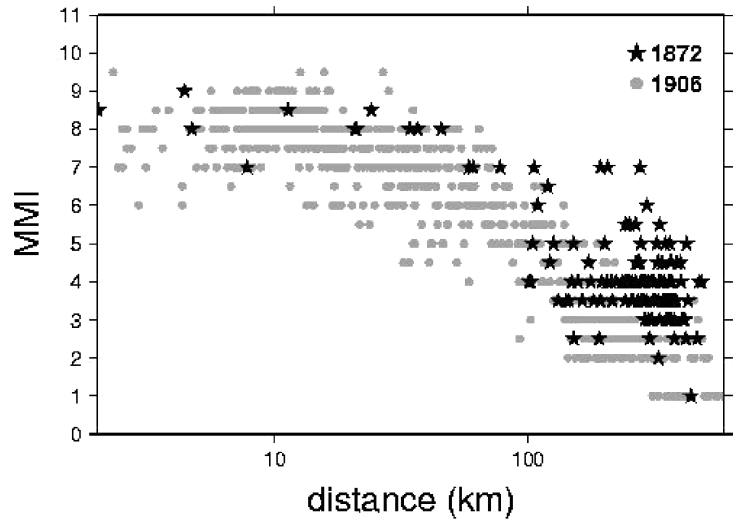

FIGURE 4. MMI values for the Owens Valley earthquake (black stars) and the 1906 San Francisco earthquake (grey circles) as estimated by Boatwright and Bundock [15].

I conclude that, while intensity assignments are inevitably uncertain to some degree, it is a robust conclusion that shaking intensities were systematically higher at regional distances in OV1872 than the 1906 earthquake. As G.K. Gilbert summarized in 1907, at a distance of only 20 miles from the San Andreas fault, "only an occasional chimney was over-turned." At 75 miles, the shock was observed by nearly all persons awake at the time; at 200 miles it was "perceived by only a few persons" [17]. The intensities assigned by Boatwright and Bundock [15] are consistent with Gilbert's descriptions. The rapid attenuation of strong shaking away from the fault is consistent with the new "Next-Generation Attenuation" (NGA) relations developed from strong motion data collected from large earthquakes around the world (see http://peer.berkeley.edu/products/nga_project.html for a description of the project and recent results.).

\section{CONCLUSIONS}

Reinterpretations of historical observations often yield lower magnitudes than earlier estimates, in large part because many (not all) early intensity assignments assigned higher values than what one would assign according to current practice. Indeed, the reinterpreted MMI values in this study are significantly lower than those assigned by Toppozada et al. [4]. However, these results confirm what was widely recognized early in the $20^{\text {th }}$ century: the shaking effects of the Owens Valley earthquake were more dramatic at regional distances than those of the 1906 San Francisco earthquake. These results therefore suggest that, of the two, OV1872 was the larger event.

The magnitude of the 1906 San Francisco earthquake can be estimated from early instrumental seismic data and early geodetic data. Recent estimates have ranged from a low of $M_{s} 7.7[18]$ to as high as Mw $7.9[19,20]$. A key question involves the 
length of the rupture, which geodetic observations suggest was longer than the break mapped following the earthquake, and the rupture length inferred from the seismic data. Song et al. [20] show that the seismic and geodetic data can be reconciled if the northernmost part of the earthquake had supershear rupture velocity. Clearly, however, the early seismic data have significant limitations, and so magnitude estimates remain uncertain.

The results of this study argue that OV1872 was larger than SF1906. If one assumes the magnitude is larger by at least 0.1 units, then, within the uncertainties of the magnitude estimates for both earthquakes, one is left with $M_{w} 7.9$ for OV1872 and $M_{w} 7.8$ for SF1906. An even larger magnitude for OV1872 is not inconsistent with available observations.

An alternative possibility is that the shaking from OV1872 was systematically higher for its magnitude than the shaking from SF1906. It is possible that OV1872 and SF1906 are representative of different classes of large earthquakes in California; respectively, they represent events on large, well-developed faults versus large events on relatively low-slip-rate faults. Sagy et al. [21] show that the surfaces of faults with low overall displacement are rougher than well-developed, high-slip faults. A number of earlier studies concluded that intraplate earthquakes, which generally occur on lowslip faults, have higher stress drops than interplate earthquakes [e.g., 22]. The results of this study suggest that there might be important differences between stress drops of interplate earthquakes.

The results of this study further provide evidence that large earthquakes (i.e., close to $M_{w} 8.0$ ) in California, and indeed other regions, are not restricted to large, high-slip faults such as the San Andreas.

\section{ACKNOWLEDGMENTS}

I thank Karen Felzer, Jack Boatwright, Bill Bakun, Gary Fuis, Tousson Toppozada, Jim Evans, Andy Michael, and Brad Aagard for constructive feedback. I also gratefully acknowledge the hospitality of the Laws Railroad Museum and the Inyo County Historical Museum.

\section{REFERENCES}

1. N.N. Ambraseys and R. Bilham, Reevaluated intensities for the great Assam earthquake of 12 June 1897, Shillong, India, Bull. Seismol. Soc. Am., 93, 655-673 (2003)

2. N.N. Ambraseys and J. Douglas, Magnitude calibration of north Indian Earthquakes, Geophys. J. Int. 159, 165-206 (2004).

3. W.H. Bakun and C.M. Wentworth, Estimating earthquake location and magnitude from seismic intensity data, Bull. Seismol. Soc. Am., 87, 1502-1521 (1997)

4. G.M. Atkinson and D.J. Wald, "Did You Feel It?" Intensity Data: A surprisingly good measure of earthquake ground motion, Seismol. Res. Lett. 78, 362-368 (2007). 
5. S.E. Hough and P. Pande, Quantifying the "media bias" in intensity surveys: lessons from the 2001 Bhuj, India earthquake, Bull. Seismol. Soc. Am. 97, 637-645 (2007).

6. S.E. Hough, L. Seeber, J.G. Armbruster, and J.F. Hough, On the modified Mercalli intensities and magnitudes of the 1811-1812 New Madrid, central United States earthquakes, J. Geophys. Res., 105, 23,839-23,864 (2000).

7. W.A. Chalfant, The Story of Inyo, Bishop: Community Printing and Publishing, 1975, pp 239-249.

8. J.D. Whitney, The Owens Valley earthquake, Part I, Vol. IX, 130-140, Overland Monthly (1872a).

9. J.D. Whitney, The Owens Valley earthquake, Part II, Vol. IX, 266-278, Overland Monthly (1872b).

10. S. Beanland and M. Clark, The Owens Valley fault zone, eastern California, and surface faulting associated with the 1872 earthquake, U.S. Geol. Surv. Bull. 1982 (1994).

11.E. Vittori, G.A. Carver, S. Jayko, A.M. Michetti, and D.B. Slemmons, Quaternary fault map of Owens Valley, eastern California, $16^{\text {th }}$ INQUA Conference Program with Abstracts, 106 (2003).

12. E.S. Holden, List of recorded earthquakes in California, Lower California, Oregon, and Washington Territory, Sacramento: State printing office, 1887, pp. 59-60.

13. C.F. Richter, Elementary Seismology, W.H. Freeman, San Francisco, 1958, pp. 499-501.

14. T.R. Toppozada, C.R. Real, and D.L. Parke, Preparation of isoseismal maps and summaries of reported effects of pre-1900 California earthquakes, California Division of Mines and Geology Open-File Rep. 81-11 (1981).

15. J. Boatwright and H. Bundock, Modified Mercalli intensity maps for the 1906 San Francisco earthquake plotted in ShakeMap format, in U.S. Geol. Surv. Open-File Rep. 2005-1135.

16. D.J. Wald, V. Quitoriano, T.H. Heaton, and H. Kanamori, Relationships between peak ground acceleration, peak ground velocity, and modified Mercalli intensity in California, Earthq. Spectra 15, 557-564 (1999).

17.G.K. Gilbert, The investigation of the California earthquake of 1906, in The California Earthquake of 1906, Jordan, D.S. ed., San Francisco: A.M. Robertson, 1907, pp. 215-256.

18. D.J. Wald, H. Kanamori, D.V. Helmberger, and T.H. Heaton, Source study of the 1906 San Francisco earthquake, Bull. Seismol. Soc. Am. 83, 981-1019 (1993).

19. W. Thatcher, G. Marshall, and M. Lisowski, Resolution of fault slip along the 470-km-long rupture of the great 1906 San Francisco earthquake and its implications, J. Geophys. Res. 103, 5353-5367, (1997).

20. S.G. Song,, G.C. Beroza, and P. Segall, A unified source model for the 1906 San Francisco earthquake, in press, Bull. Seismol. Soc. Am. 98 (2008).

21. A. Sagy, E.E. Brodsky, and G.J. Axen, Evolution of fault-surface roughness with slip, Geology 35, 283-286, 2007.

22. C.H. Scholz, The mechanics of earthquakes and faulting, $2^{\text {nd }}$ edition, New York: Cambridge Univ. Press, 2002, pp. 206-212. 